\title{
Apoptosis induced by 7-difluoromethoxyl-5,4'-di-n-octyl genistein via the inactivation of FoxM1 in ovarian cancer cells
}

\author{
YINGXIA NING ${ }^{1}$, QINGXIU LI ${ }^{1}$, HONGLIN XIANG ${ }^{2}$, FEI LIU $^{2}$ and JIANGUO CAO ${ }^{2}$ \\ ${ }^{1}$ The First Affiliated Hospital of Guangzhou Medical College, Guangzhou 510120; \\ ${ }^{2}$ Medical College, Hunan Normal University, Changsha 410013, P.R. China
}

Received November 29, 2011; Accepted February 10, 2012

DOI: 10.3892/or.2012.1739

\begin{abstract}
Genistein, 5,7,4'-trihydroxylisoflavone, a major component of soybean products, has been reported to possess anticancer activities. We examined the antitumor effects of 7-difluoromethoxyl-5,4'-di-n-octylgenistein (DFOG), a novel synthetic genistein derivative, on human ovarian cancer cells as well as the molecular mechanism. The growth-inhibitory effects of genistein and DFOG were determined using MTT assay and clonogenic assay in $\mathrm{CoC} 1$ and SKOV3 human ovarian cancer cells. Apoptotic activities of DFOG were observed using histone/DNA ELISA assay and flow cytometry with propidium iodide (PI) staining. Multiple molecular techniques, such as RT-PCR, western blot analysis, siRNA and cDNA transfection were used to explore the molecular mechanism. We demonstrated that nine of the genistein derivatives had a more effective antitumor activity than genistein. Among the afore-mentioned derivatives, DFOG presented with the strongest activity against $\mathrm{CoC} 1$ and $\mathrm{SKOV} 3$ cells in vitro. DFOG and genistein inhibited the growth of $\mathrm{CoC} 1$ and SKOV 3 cells, accompanied by cell cycle arrest in the G2/M phase. DFOG caused apoptotic cell death with concomitant attenuation of Forkhead box protein M1 (FoxM1) and its downstream genes, such as survivin, CDC25B, cyclin B, and increased $\mathrm{p} 27^{\mathrm{KIP} 1}$. Downregulation of FoxM1 by siRNA followed by DFOG treatment resulted in enhanced cell growth inhibition and induction of apoptosis. Upregulation of FoxM1 by cDNA transfection attenuated DFOG-induced cell growth inhibition and apoptotic cell death. Our results show that the molecular role of FoxM1 in mediating the biological effects of DFOG and genistein in human ovarian cancer cells suggests that FoxM1 could be a novel target for the treatment of human ovarian cancer.
\end{abstract}

Correspondence to: Dr Jianguo Cao, Medical College, Hunan Normal University, Changsha 410013, P.R. China

E-mail: caojianguo2005@yahoo.com.cn

Key words: ovarian cancer, genistein, 7-difluoromethoxyl-5, 4'-di-n-octylgenistein, apoptosis, Forkhead box protein M1

\section{Introduction}

Epithelial ovarian cancer (EOC) is the leading cause of gynecologic cancer death (1). This high mortality rate is associated with difficulties in diagnosis of the early stages of the disease and because of a high rate of recurrence $(2,3)$. Although $80 \%$ of cancers initially respond to chemotherapy, the majority ultimately reoccurs with less than $15 \%$ remaining in remission (4). Therefore, the need for a new drug for the prevention and treatment of ovarian cancer is urgent.

Genistein (5,7,4'-trihydroxyisoflavone) is an isoflavone found in soy products that has been shown to affect the cell cycle progression and apoptosis in various cancer cell lines $(5,6)$. The low absorption of genistein in the intestine and the rapid metabolic elimination resulting from the hydroxyls at the C-5, C-7, and C-4' positions allows genistein to bind to glucuronic and sulfuric acid, and reduce its bioavailability and bioactivity in vivo (7), thus restricting its clinical application. Recently, we synthesized a series of difluoromethoxylated genistein derivatives and determined their protective effects against vascular endothelial cells (8). There are only a few studies reported on the anticancer effects of fluorinated genistein derivatives.

EOC has been shown to have an activated Forkhead box protein M1 (FoxM1) signaling pathway (9). The FoxM1 belongs to a family of evolutionary conserved transcriptional regulators that are characterized by the presence of a DNA-binding domain called the Forkhead box domain (10). Many studies have shown that FoxM1 signaling plays important roles in cellular developmental pathways, and thus, activation of FoxM1 signaling has been reported to be associated with carcinogenesis (11). FoxM1 signaling is frequently upregulated in cancers, including lung, breast, pancreatic and ovarian cancer $(9,12-14)$. Moreover, FoxM1 has been shown to regulate the transcription of cell cycle genes, including $\mathrm{CDC} 25 \mathrm{~B}$, cyclin $\mathrm{B}$, and $\mathrm{p} 27^{\mathrm{KIP} 1}$, and apoptosis-relative genes, such as survivin $(10,15)$. Studies by Wang et al have shown that genistein may inhibit FoxM1 activation in pancreatic cancer cells, leading to apoptotic cell death (16). Accordingly, we hypothesized that that genistein and the novel synthetic genistein derivative DFOG (7-difluoromethoxyl-5,4'-di-noctylgenistein) may target the inactivation of FoxM1, which could represent a promising strategy for ovarian cancer therapy. 
Table I. The structures of genistein and its difluoromethylated derivatives.

\begin{tabular}{|c|c|c|c|c|}
\hline & & Compound & $\mathrm{R}_{1}$ & $\mathrm{R}_{2}$ \\
\hline & 1 & Genistein ( 5,7,4'-trihydroxylisoflavone ) & $\mathrm{H}$ & $\mathrm{H}$ \\
\hline & 2 & 7-difluoromethyl genistein & CHF2 & $\mathrm{H}$ \\
\hline & $4 a$ & 7-difluoromethyl-5,4'-dimethyl genistein & CHF2 & $\mathrm{CH} 3$ \\
\hline & $4 b$ & 7-difluoromethyl-5,4'-diethyl genistein & CHF2 & $\mathrm{CH} 3 \mathrm{CH} 2$ \\
\hline & $4 c$ & 7-difluoromethyl-5,4'-di-n-propyl genistein & CHF2 & $\mathrm{n}-\mathrm{C} 3 \mathrm{H} 7$ \\
\hline & $4 d$ & 7-difluoromethyl-5,4'-di-benzyl genistein & $\mathrm{CHF} 2$ & $\mathrm{C} 6 \mathrm{H} 5 \mathrm{CH} 2$ \\
\hline & $4 \mathrm{e}$ & 7-difluoromethyl-5,4'-diheptyl genistein & $\mathrm{CHF} 2$ & $\mathrm{n}-\mathrm{C} 7 \mathrm{H} 15$ \\
\hline & $4 f$ & 7-difluoromethyl-5,4'-di-n-octyl genistein & $\mathrm{CHF} 2$ & $\mathrm{n}-\mathrm{C} 8 \mathrm{H} 17$ \\
\hline & $4 \mathrm{~g}$ & 7-difluoromethyl-5,4'-didecyl genistein & $\mathrm{CHF} 2$ & $\mathrm{n}-\mathrm{C} 10 \mathrm{H} 21$ \\
\hline & $4 \mathrm{~h}$ & 7-difluoromethyl-5,4'-diisobutyl genistein & CHF2 & Iso-C4H9 \\
\hline
\end{tabular}

In this study, we investigated whether DFOG and genistein inhibit the growth of ovarian cancer cells and could be attributed to the inhibition of FoxM1 expression. We found that DFOG and genistein downregulated the FoxM1 expression and its downstream genes, including survivin, CDC25B, and cyclin $\mathrm{B}$, and increased $\mathrm{p} 27^{\mathrm{KIP} 1}$, resulting in the induction of growth inhibition and apoptosis in ovarian cancer cells. These results provide supportive evidence for the first time that FoxM1 is a legitimate target in ovarian cancer and that the targeted inactivation of FoxM1, especially by the novel synthetic derivative of genistein, DGOG and genistein as shown here, would be highly relevant for designing novel strategies for the prevention of tumor progression and/or treatment of ovarian cancer.

\section{Materials and methods}

Cell culture and experimental reagents. The human ovarian cancer cell lines $\mathrm{CoC1}$ and SKOV3 were purchased from the China Centre for Type Culture Collection (CCTCC; Wuhan, China) and were maintained in DMEM medium (Invitrogen Corp., Carlsbad, CA, USA) supplemented with $10 \%$ fetal bovine serum, $4 \mathrm{mM}$ glutamine, $100 \mathrm{U} / \mathrm{ml}$ penicillin, and $100 \mu \mathrm{g} / \mathrm{ml}$ streptomycin, and incubated at $37^{\circ} \mathrm{C}$ in a humidified atmosphere of $5 \% \mathrm{CO}_{2}$. The difluoromethoxylated genistein derivatives $2,4 \mathrm{a}-4 \mathrm{~h}$ were prepared via the afore-mentioned method (8) (Table I). Primary antibodies for FoxM1, survivin, cyclin $\mathrm{B}, \mathrm{p} 27^{\mathrm{KIP} 1}, \mathrm{CDC} 25 \mathrm{~B}$, and $\beta$-actin, as well as horseradish peroxidase-conjugated rabbit anti-mouse secondary antibody were purchased from Santa Cruz Biotechnology (Santa Cruz, CA, USA). Lipofectamine 2000 was purchased from Invitrogen. Protease inhibitor cocktail, 3-(4,5-dimethylthiazol-2-yl)-2,5-diphenyltetrazolium bromide (MTT), and all other chemicals were obtained from Sigma-Aldrich, St. Louis, MO, USA. Genistein and the difluoromethoxylated genistein derivatives were dissolved in dimethyl sulfoxide (DMSO) to make a $10 \mathrm{mM}$ stock solution and were added directly to the media at different concentrations.

MTT assay. Cells were seeded in a 96-well plate at a density of 5,000 cells/well as previously described (17). After incubation for $24 \mathrm{~h}$, different concentrations of genistein and genistein derivatives $(0.1,0.3,1.0,3.0,10.0$ and $30.0 \mu \mathrm{mol} / \mathrm{l})$ were added to each well and cultured for $48 \mathrm{~h}$. The medium was removed and then incubated with $5 \mathrm{mg} / \mathrm{l}$ MTT for $4 \mathrm{~h}$. Next, the supernatant was removed after centrifugation. Finally, $100 \mu \mathrm{l}$ of DMSO was added and an absorbance at $570 \mathrm{~nm}$ wavelength $\left(\mathrm{A}_{570}\right)$ was measured by means of an Enzyme-Labeling Instrument (ELX-800 type; BioTek, Shanghai, China). Relative cell proliferation inhibition rate $(I R)=\left(1\right.$-average $A_{570}$ of the experimental group/average $\mathrm{A}_{570}$ of the control group) $\mathrm{x} 100 \%$. The $\mathrm{IC}_{50}$ (defined as the drug concentration, of which $50 \%$ cell viability was inhibited) was assessed from the dose-response curves using GraphPad Prism program (version 4; GraphPad Software, Inc., La Jolla, CA, USA).

Clonogenic assay. Cells were plated in 24-well plates at a density of 300 cells/well for $24 \mathrm{~h}$ prior to the addition of various concentrations of DFOG $(1,5$ and $10 \mu \mathrm{mol} / \mathrm{l})$ and $10 \mu \mathrm{mol} / 1$ genistein. After $48 \mathrm{~h}$ of treatment, the drugcontaining medium was removed and replaced with complete growth medium. Medium was changed every 3 days for 7 to 10 days until visible colonies formed. Colonies were simultaneously fixed and stained with Wright-Giemsa solution in methanol and manually counted. Individual stained colonies in each well were counted and the colony formation fraction was calculated as follows: colony number/(number of cells seeded $\mathrm{x}$ plating efficiency), where plating efficiency is equivalent to the colony number divided by the number of cells seeded in the drug-free medium. 
FCM analysis using propidium iodide staining. Cells were seeded at a density of $4 \times 10^{6}$ cells/well in $100-\mathrm{ml}$ culture flasks for $24 \mathrm{~h}$ and then treated with the medium containing various concentrations of the testing agents and $10 \%$ fetal bovine serum for $24 \mathrm{~h}$. Propidium iodide (PI) staining for DNA content analysis was performed as previously described (18).

Histone/DNA ELISA for detecting apoptosis. The cell apoptosis ELISA detection kit was used to detect apoptosis in cells treated with DFOG and genistein according to the manufacturer's protocol. Briefly, cells were seeded in a 96-well plate at a density of $1 \times 10^{4}$ cells/well for $24 \mathrm{~h}$, and the testing agents were then added to the culture medium containing $10 \%$ fetal bovine serum. After $48 \mathrm{~h}$, we transferred the cytoplasm of the control and treatment groups to the 96 -well plate pre-coated with streptavidin that had been previously incubated with the biotinylated histone antibody and peroxidase-tagged mouse anti-human DNA for $2 \mathrm{~h}$ at room temperature. The absorbance was measured at $405 \mathrm{~nm}$ with the EXL-800-type enzymelinked immunosorbent apparatus.

Reverse transcription-PCR. Total RNA was extracted using TRIzol reagent (Life Technologies, Inc., Gaithersburg, MD, USA). The integrity of the RNA was checked by $2 \%$ agarose gel electrophoresis. Approximately $2 \mu \mathrm{g}$ RNA was reversetranscribed following the protocol of the Super Script ${ }^{\mathrm{TM}}$ First-Strand Synthesis System (Invitrogen Corp., Carlsbad, CA, USA). CDNAs encoding FoxM1 and glyceraldehyde3-phosphate dehydrogenase (GAPDH) genes were amplified by PCR as follows: denaturation at $94^{\circ} \mathrm{C}$ for $30 \mathrm{sec}$, annealing at $63^{\circ} \mathrm{C}$ for $30 \mathrm{sec}$, and elongation at $72^{\circ} \mathrm{C}$ for $45 \mathrm{sec}$. Primer sequence was performed in accordance with Wang et al (19). For FoxM1, the forward primer was (5'-AACCGCTACTTG ACATTGG-3') and reverse primer was (5'-GCAGTGGCTT CATCTTCC-3'). A housekeeping gene, GAPDH, was used as the internal control. The forward primer was 5'-ACCCAGAA GACTGTGGATGG-3', and the reverse primer was 5'-TGCTGT AGCCAAATTCGTTG-3'. PCR products were analyzed by agarose (2\%) gel electrophoresis, and the amplicon size for FoxM1 was $358 \mathrm{bp}$, and for GAPDH it was $473 \mathrm{bp}$.

Plasmids and transfections. FoxM1 siRNA and siRNA controls were obtained from Santa Cruz Biotechnology. The FoxM1 cDNA plasmid was purchased from OriGene Technologies Inc. (Rockville, MD, USA). Human ovarian cancer SKOV3 cells were transfected with FoxM1, siRNA, and cDNA, respectively, using Lipofectamine 2000 (Invitrogen) as described by Wang et al (19).

Western blot analysis. Western blot analysis was carried out as previously described (18). Anti-FoxM1, anti-cyclin B, anti-p27 ${ }^{\mathrm{KIP} 1}$, anti-CDC25B, anti-survivin, and anti- $\beta$-actin were used as primary antibodies. Cells were lysed in a lysis buffer by incubating for $20 \mathrm{~min}$ at $4^{\circ} \mathrm{C}$. The protein concentration was determined by using the Bio-Rad assay system (Bio-Rad Laboratories, Inc., Hercules, CA, USA). Total proteins were fractionated using SDS-PAGE and transferred onto Polyvinylidene fluoride membrane (PVDF) (Millipore, Billerica, MA, USA). The signals were detected using an
ECL Advance Western Blotting Analysis System (Amersham Pharmacia Biotech Inc., Piscataway, NJ, USA).

Statistical analysis. The database was set up with the SPSS 15.0 software package (SPSS Inc., Chicago, IL, USA) for analysis. Data are presented as the mean \pm SD. The means of multiple groups were compared with one-way ANOVA, after the equal check of variance, and the comparisons among the means were performed using the LSD method. Statistical comparison was also performed with two-tailed t-test when appropriate. $\mathrm{P}<0.05$ was considered as statistically significant.

\section{Results}

Effects of genistein and genistein derivatives on cell growth inhibition and cycle arrest of ovarian cancer cells. First, we examined the effect of genistein and the genistein derivatives on cell viability of SKOV3 and $\mathrm{CoC} 1$ cells using MTT assay. Nine of difluoromethylated genistein derivatives had more effective antitumor activities than genistein. Among the derivatives tested, DFOG showed the strongest activity against SKOV3 and $\mathrm{CoC} 1$ in vitro (Fig. $1 \mathrm{~A}$ and $\mathrm{B}$ ). $\mathrm{IC}_{50}$ of DFOG treated for $48 \mathrm{~h}$ was $5.6 \pm 1.3 \mu \mathrm{mol} / 1$ for SKOV3 cells and $5.3 \pm 1.2 \mu \mathrm{mol} / 1$ for $\mathrm{CoC} 1$ cells. Furthermore, the potency of DFOG was 8.6 and 9.7 times than that of the lead compound, genistein $\left(\mathrm{GEN}, \mathrm{IC}_{50}\right.$ was $48.2 \pm 4.6 \mu \mathrm{mol} / 1$ for $\mathrm{SKOV} 3$ cells and $51.41 \pm 3.6 \mu \mathrm{mol} / 1$ for $\mathrm{CoC} 1$ cells).

In order to confirm our results, we tested the effects of DFOG on cell growth by clonogenic assay. Fig. $1 \mathrm{C}$ and D show that DFOG treatment resulted in a significant inhibition of colony formation of SKOV3 cells when compared to control. Overall, the results from clonogenic assay was consistent with the MTT data as shown in Fig. 1A, suggesting that DFOG inhibits the growth of ovarian cancer cells.

Additionally, to assess whether the loss of cell viability could in part be due to the induction of cell cycle arrest, we evaluated the effects of DFOG treatment on the distribution in the cell phase using FCM after PI staining. As shown in Fig. 1E and $\mathrm{F}$, in the ovarian cancer SKOV3 cell line, DFOG treatment caused a significant accumulation of cells in the G2/M phase and a marked decrease in the G1/G0 phase when compared with control cells. The similar results were observed in $\mathrm{CoC} 1$ cells (data not shown). These results provided convincing data by showing that the novel synthetic genistein analogue DFOG induced the growth inhibition and arrest of cell cycle in G2/M phase in ovarian cancer cells.

Effect of DFOG on apoptosis in ovarian cancer cells. To assess whether the loss of cell viability could in part be due to the induction of apoptosis, we next examined the effects of DFOG and genistein on apoptosis in $\mathrm{CoC} 1$ and SKOV3 cells using different approaches. After $48 \mathrm{~h}$ of exposure, DFOG significantly induced histone/DNA fragmentation in a concentration-dependent manner (Fig. 2A and B). Fig. 2C and D show that DFOG treatment resulted in a dose-dependent increase of the Sub-G1 population in SKOV3 cells $(\mathrm{P}<0.05)$. Similar results were observed in $\mathrm{CoC} 1$ cells (data not shown). Taken together, our results provided convincing data demonstrating that DFOG and genistein were able to induce apoptosis in ovarian cancer cells. 
A

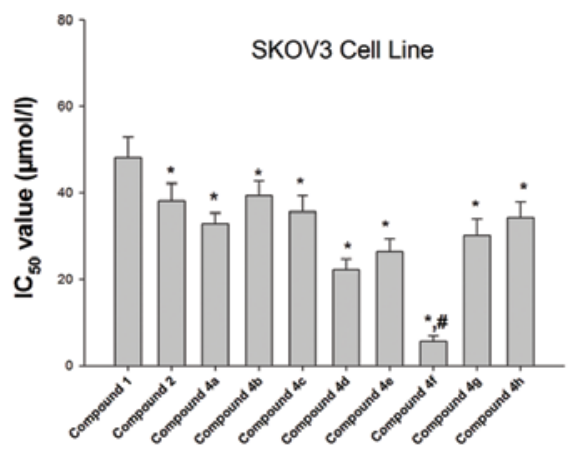

D

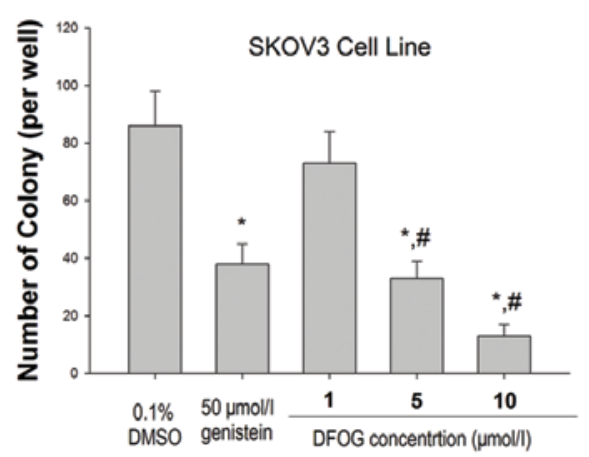

B

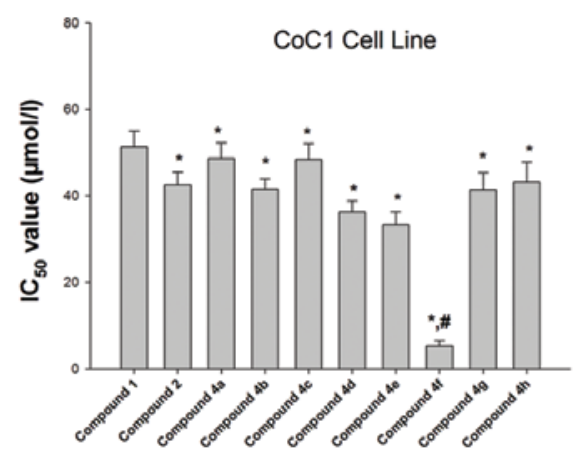

$\mathbf{E}$

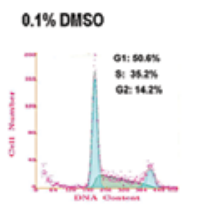

$5 \mu \mathrm{mol}$ DFOG

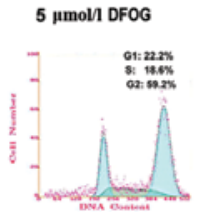

C
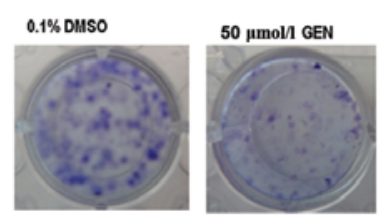

5 нmol DFOG

10 нmol/ DFOG
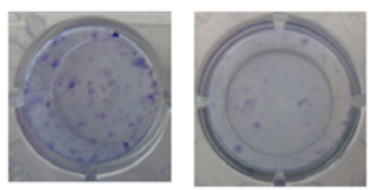

F

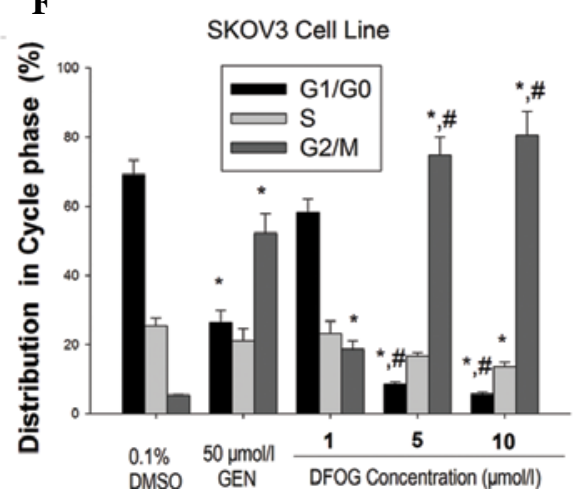

Figure 1. Inhibition of cell viability by genistein and genistein derivatives in SKOV3 (A) and CoC1 cell line (B) are shown. ${ }^{*} \mathrm{P}<0.05$ vs. treatment with DMSO; ${ }^{\#} \mathrm{P}<0.05$ vs. treatment with genistein or other genistein derivatives. Decrease of colony number (C) and inhibition of colony formation (D) by DFOG and genistein in SKOV3 cell line. Increase of cells in G2/M phase (E) and induction of cell cycle arrest in G2/M phase (F) by DFOG and genistein in SKOV3 cell line. ${ }^{*} \mathrm{P}<0.05$ vs. treatment with DMSO; ${ }^{*} \mathrm{P}<0.05$ vs. treatment with $50 \mu \mathrm{mol} / 1 \mathrm{GEN}$ or $1 \mu \mathrm{mol} / 1 \mathrm{DFOG}$.

$\mathbf{A}$

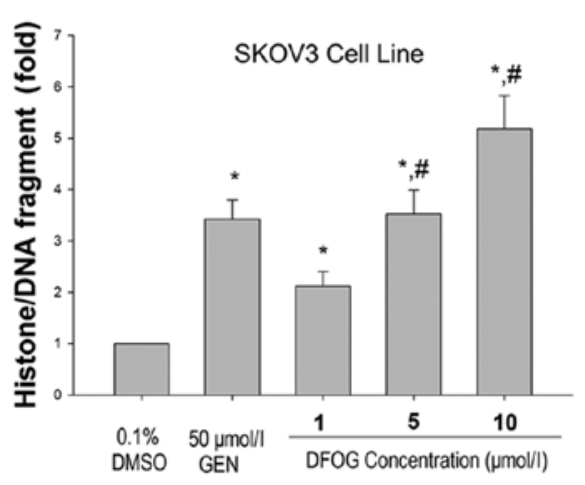

C
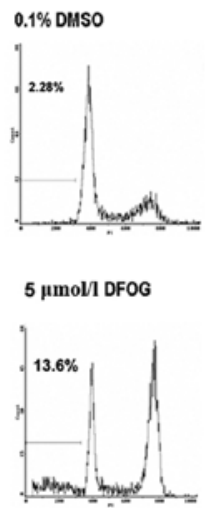

$50 \mu \mathrm{mol} / \mathrm{GEN}$
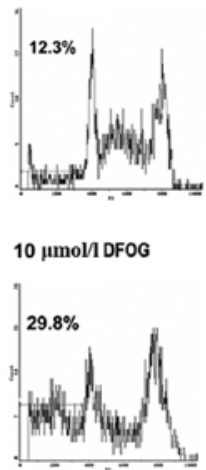

B

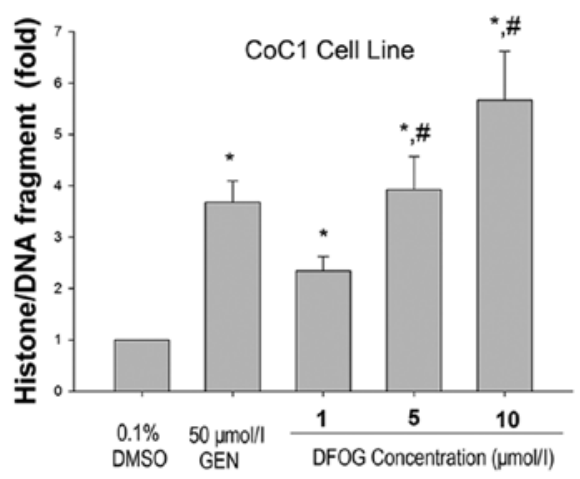

D

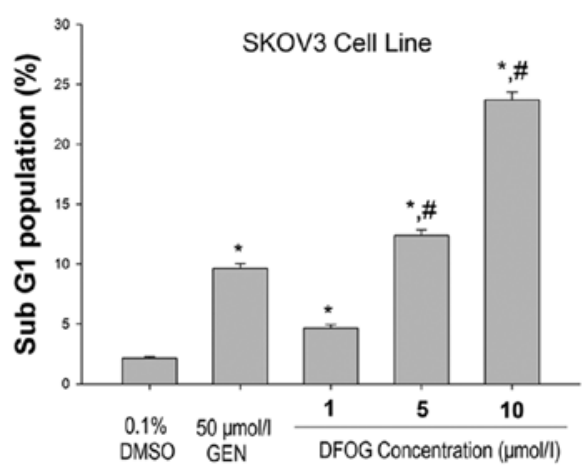

Figure 2. Increase of histone/DNA fragment levels by DFOG and genistein in SKOV3 (A) and CoC1 (B) cells is illustrated. Promotion of the Sub-G1 population by DFOG and genistein in SKOV3 cells (C and D). ${ }^{*} \mathrm{P}<0.05$ vs. treatment with DMSO; ${ }^{*} \mathrm{P}<0.05$ vs. treatment with $50 \mu \mathrm{mol} / 1 \mathrm{GEN}$ or $1 \mu \mathrm{mol} / 1 \mathrm{DFOG}$. 
A

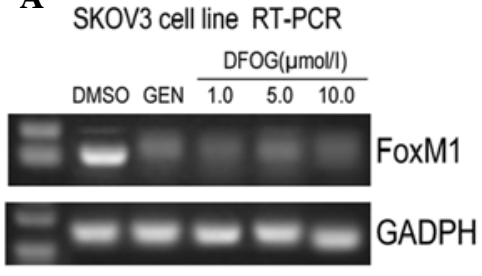

C

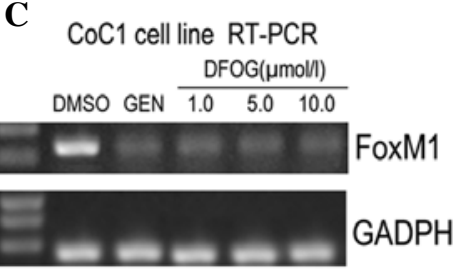

B

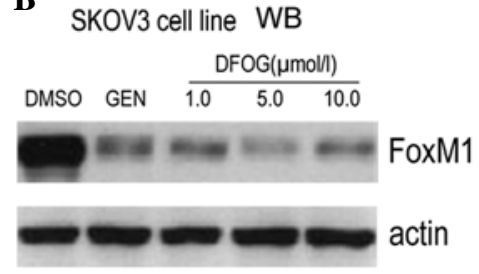

D

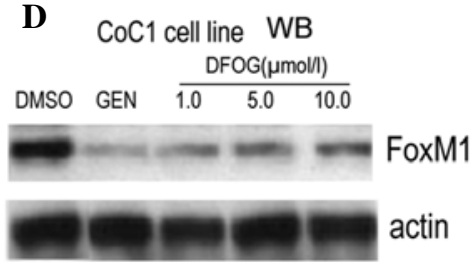

Figure 3. The downregulation of FoxM1 expression by DFOG and genistein at mRNA level using RT-PCR in SKOV3 (A) and CoC1 (C) cell lines and protein level using western blotting in SKOV3 (B) and $\mathrm{CoC1}$ (D) cell lines is shown.

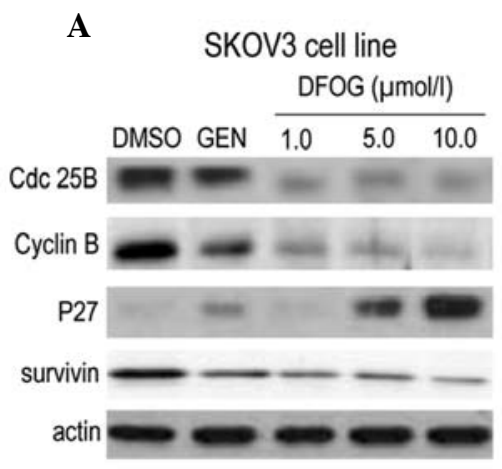

B

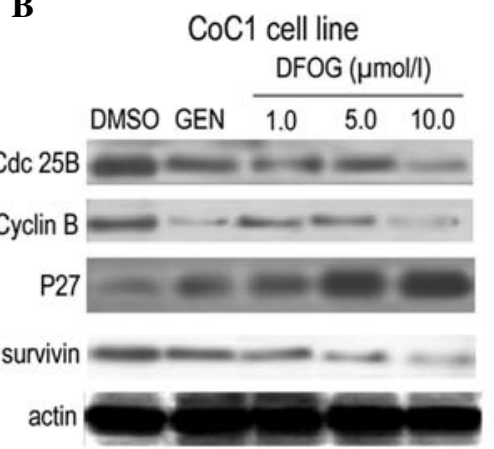

Figure 4. Shown is the modulation of the protein expressions of FoxM1 downstream target genes by DFOG and genistein in SKOV3 (A) and CoC1 (B) cell lines.

Effect of DFOG on the expression of FoxM1 in ovarian cancer cells. Because genistein has been shown to inhibit FoxM1 activation in pancreatic cancer cells, leading to apoptotic cell death (16), we investigated whether DFOG could regulate FoxM1 signaling pathways using molecular and mechanistic approaches. The expression of FoxM1 was determined using RT-PCR and western blot analysis, respectively. The results showed that FoxM1 was overexpressed in SKOV3 (Fig. 3A and B) and $\mathrm{CoC1}$ (Fig. 3C and D) cell lines. We found that FoxM1 was downregulated by DFOG in SKOV3 (Fig. 3A and B) and CoC1 (Fig. 3C and D) cells.

Effect of DFOG on the expression of FoxM1 downstream target genes in ovarian cancer cells. To further confirm the effect on FoxM1 by DFOG and genistein, we next assessed the expression of FoxM1 downstream target genes in SKOV3 and $\mathrm{CoC} 1$ cells after DFOG and genistein treatment. It is well known that FoxM1 has several downstream target genes, such as $\mathrm{CDC} 25 \mathrm{~B}$, cyclin $\mathrm{B}$, survivin and $\mathrm{p} 27^{\mathrm{KIP} 1}$. To determine the expression of these proteins, we used western blot analysis. We found that DFOG inhibited the expression of CDC25B, cyclin $\mathrm{B}$, and survivin, and increased $\mathrm{p} 27^{\mathrm{KIP} 1}$ at the protein levels in SKOV3 (Fig. 4A) and CoC1 (Fig. 4B) cells.
Effect of downregulation of FoxM1 expression by siRNA on DFOG-induced growth inhibition and apoptosis in SKOV3 cells. Downregulation of FoxM1 by siRNA transfection showed less expression of FoxM1 protein in SKOV3 cells, as confirmed by western blotting (Fig. 5A). Furthermore, we found that the downregulation of FoxM1 expression by DFOG significantly inhibited cell viability (Fig. 5B) and induced apoptotic cell death in SKOV3 (Fig. 5C and D). In addition, DFOG plus FoxM1 siRNA inhibited cell growth and induced apoptosis to a greater degree compared with DFOG alone (Fig. 5B-D). These results provide some molecular evidence suggesting the DFOG-induced inhibition of the growth and apoptosis is mediated via the inactivation of FoxM1 in ovarian cancer cells.

Effects of overexpression of FoxM1 by cDNA transfection on DFOG-induced cell growth inhibition in SKOV3 cells. Upregulation of FoxM1 by cDNA transfection showed an overexpression of FoxM1 protein in SKOV3 cells, as confirmed by western blotting (Fig. 6A). The results showed that overexpression of FoxM1 rescued DFOG-induced cell viability inhibition to a certain degree (Fig. 6B) and apoptotic cell death (Fig. 6C and $\mathrm{D})$. These results provide mechanistic evidence suggesting 
A

SKOV3 Cell Line

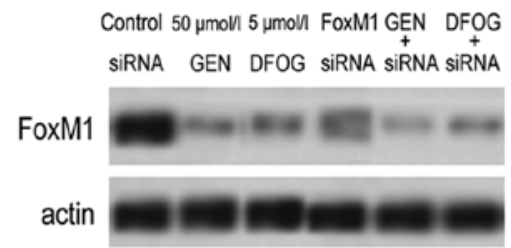

C

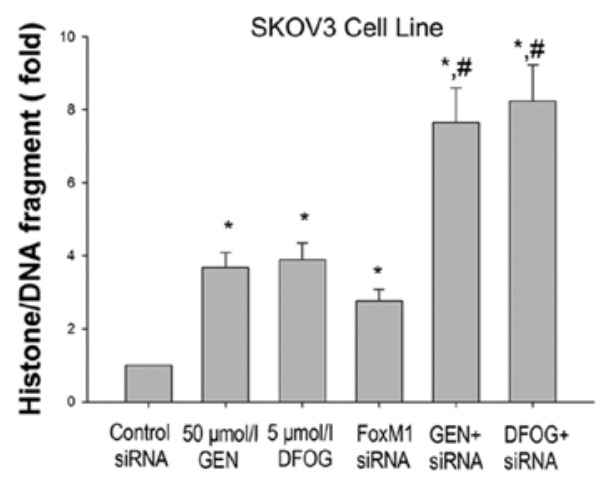

B

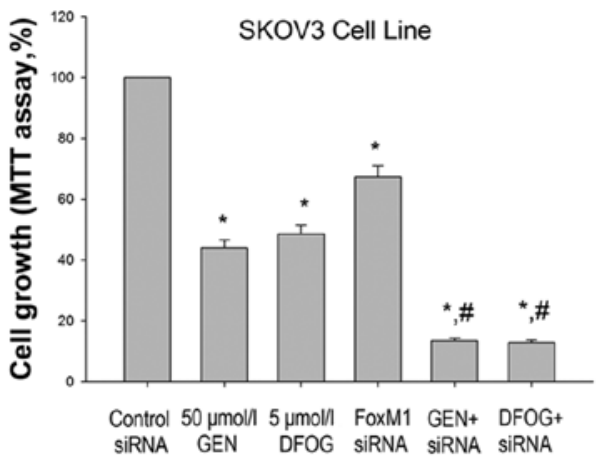

D

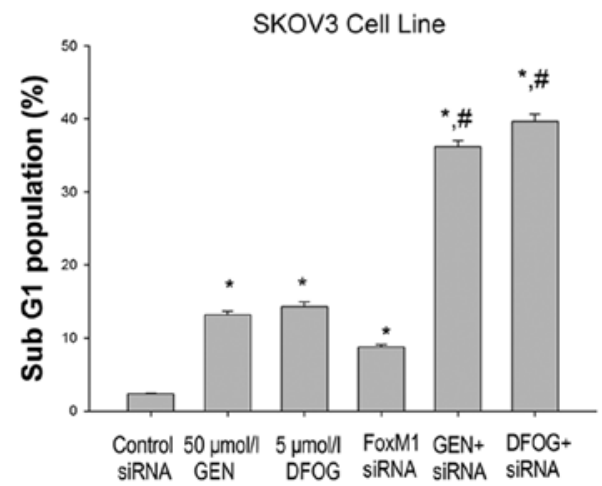

Figure 5. FoxM1 siRNA enhances the downregulation of FoxM1 protein expression by DFOG and genistein using western blot analysis (A), inhibition of cell growth by MTT assay (B), induction of histone/DNA fragment levels using ELISA (C), and increase of the Sub-G1 population using flow cytometry analysis (D) in SKOV3 cell line. " $\mathrm{P}<0.05$ vs. treatment with DMSO; " $\mathrm{P}<0.05$ vs. treatment with $5 \mu \mathrm{mol} / 1 \mathrm{DFOG}$ or FoxM1 siRNA alone.

A

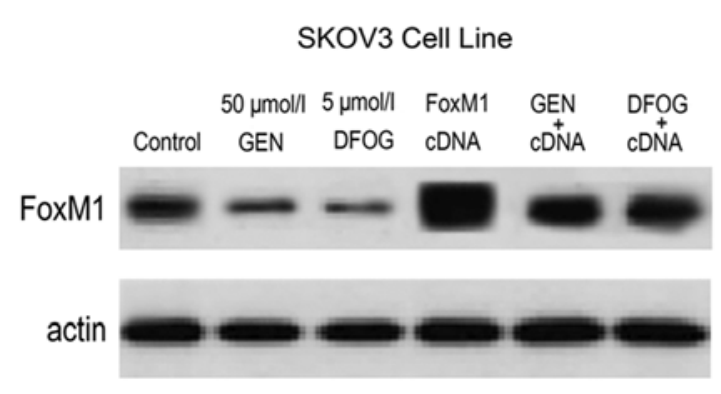

C

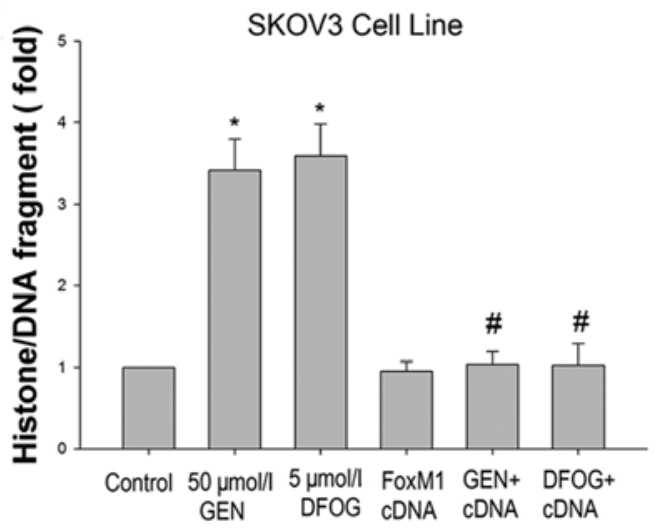

B
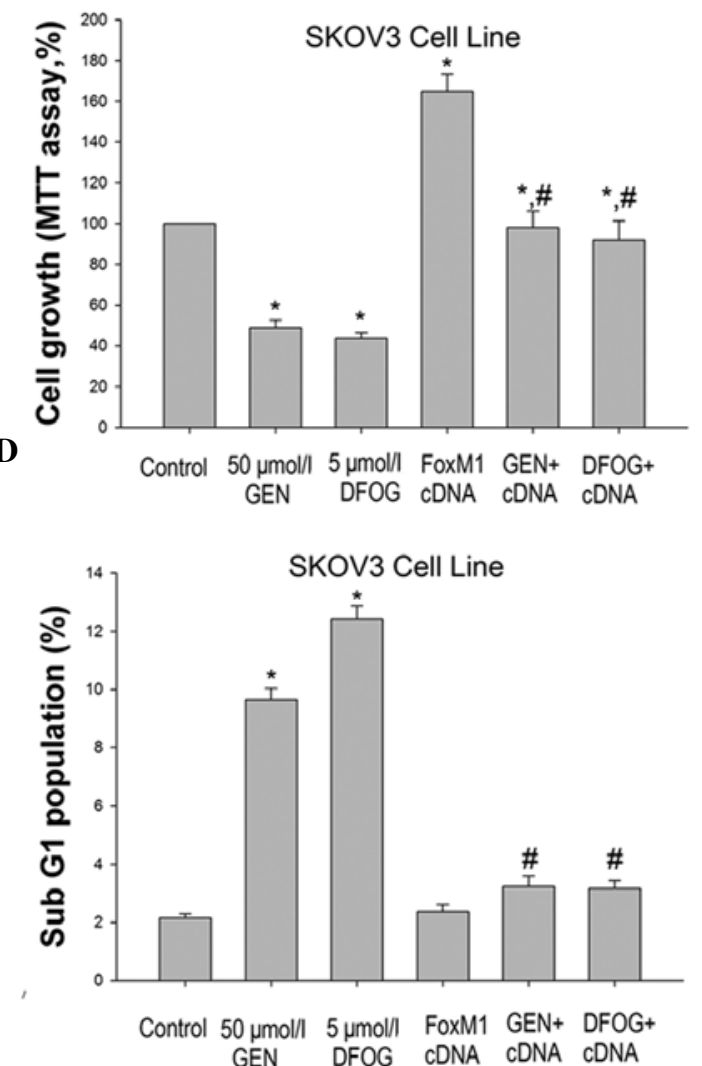

Figure 6. FoxM1 cDNA transfection reduces the downregulation of FoxM1 protein expression by DFOG and genistein using western blot analysis (A), inhibition of cell growth by MTT assay (B), induction of histone/DNA fragment levels using ELISA (C), and increase of Sub-G1 population using flow cytometry analysis (D) in SKOV3 cell line. ${ }^{*} \mathrm{P}<0.05$ vs. treatment with DMSO; ${ }^{*} \mathrm{P}<.05$ vs. treatment with $5 \mu \mathrm{mol} / 1 \mathrm{DFOG}$ or FoxM1 cDNA transfection alone. 
that the DFOG inhibited cell growth is in part due to the inactivation of FoxM1 signaling pathway in ovarian cancer cells.

\section{Discussion}

A variety of studies have shown overexpression of FoxM1 gene in human cancer cells and tissues, including ovarian cancer (9,11-14,19-22), and this emerging evidence suggests that the inactivation of FoxM1 may play an important role in cancer therapy. For example, FoxM1 could be downregulated by some drugs, such as siomycin A, thiostrepton, and EGFR inhibitor gefitinib (22-24). The study by Wang et al found that genistein inhibited FoxM1 activation in pancreatic cancer cells, leading to cell growth inhibition and induction of apoptosis (16). Thus, in the present study, we investigated whether the novel synthetic genistein derivative DFOG and genistein induce inhibition of cell viability and induction of apoptotic cell death and the role of FoxM1 in ovarian cancer cell lines. In our study, DFOG and genistein elicited a dramatic inhibitory effect on the growth of ovarian canser cells as shown by MTT and clonogenic assay, accompanied by downregulation of FoxM1 expression. Our results suggest that FoxM1 as a target of DFOG and genistein in ovarian cancer cells because FoxM1 is known to induce oncogenesis, and its downregulation causes inhibition of cell growth (25-27). Undeniably, we found that downregulation of FoxM1 by siRNA together with DFOG treatment inhibited cell growth to a greater degree in SKOV3 cells compared to DFOG treatment alone. Upregulation of FoxM1 by cDNA transfection showed overexpression of FoxM1 protein as confirmed by western blot analysis, and this overexpression in FoxM1 attenuated DFOG-induced cell growth inhibition and apoptotic cell death in SKOV3 cells.

Many studies showed that FoxM1 promotes cell growth and stimulates the expression of genes critical for the G1/S transition, S-phase progression, the G2/M transition, and M-phase progression (28-30). Because downregulation of FoxM1 by DFOG or genistein reduced cell growth, we investigated whether cell growth inhibition was due to cell cycle arrest in any specific phase of the cell cycle. We found that treatment with DFOG or genistein increased cell population in the G2/M phase and decreased cells in the G1 and S phase. Diminished cell population of cells in G1 and S phase and growth rate was associated with increased expression of the CdkI protein $\mathrm{p} 27^{\mathrm{KIP} 1}$, which is known to have negative effects on cell cycle machinery by binding to various cyclin-Cdk complexes and inhibiting their activities $(28,29)$. FoxM1 includes CDC25B phosphatase, which is important for the activation of Cdk1, and a number of the genes encoding proteins essential for the correct execution of mitosis such as Plk1 kinase, AurkB, CENPB, and survivin (30). We observed a marked reduction of CDC25B and cyclin B expression in cells treated with DFOG and genistein. In our study, the decrease in CDC25, cyclin $\mathrm{B}$, and the increased expression of $\mathrm{p} 27^{\mathrm{KIPl}}$ were strongly correlated with the altered cell cycle distribution phenotype and growth suppression. These results suggest that DFOG and genistein affects the ovarian cancer cell cycle by regulating the expression levels of $\mathrm{CDC} 25 \mathrm{~B}$, cyclin $\mathrm{B}$, and $\mathrm{CDK}$ inhibitors p2 $7^{\mathrm{KIP} 1}$ through downregulation of FoxM1 expression.

In addition, survivin, an inhibitor of apoptosis and a key regulator of mitosis, is upregulated in a variety of cancer cells and is often associated with a worse prognosis (31). Notably, several studies have shown that FoxM1 can regulate survivin expression $(32,33)$. Therefore, we examined the effects of DFOG and genistein on apoptosis and the expression of FoxM1 and its downstream target, survivin. Our results show that DFOG and genistein efficaciously induced apoptotic cell death of ovarian cancer cells. Furthermore, DFOG and genistein inhibited the expression of FoxM1 and survivin. Therefore, DFOG and genistein-induced apoptotic cell death could be partly mediated via the inactivation of FoxM1 activity. We found that the downregulation of FoxM1 by siRNA together with either DFOG or genistein treatment induced apoptosis to a greater degree in ovarian cancer cells when compared to DFOG or genistein treatment alone. In view of these findings, we strongly believe that the inactivation of FoxM1 by DFOG and genistein results in the downregulation of its target genes, which are believed to be mechanistically linked with inhibition of cell growth and induction of apoptosis by treatment with DFOG or genistein.

In summary, we presented experimental evidence that strongly supports the role of DFOG, a novel genistein derivative, as an antitumor agent mediated through inactivation of FoxM1 signaling pathway. Further in depth investigations are necessary in order to identify how DFOG could regulate the FoxM1 pathway, and further studies are also warranted to assess the antitumor activity mediated by the inactivation of FoxM1 by either genistein, DFOG, or other synthetic compounds in preclinical animal models for the successful treatment of ovarian cancer. It is also tempting to speculate that the inactivation of FoxM1 together with the treatment of ovarian cancer cells with conventional agents could be a useful strategy toward better treatment.

\section{Acknowledgements}

This study was supported by the Project of Scientific Research of Hunan Province the Administration Bureau of Traditional Chinese Medicine (no. 2010081), the Project of Scientific Research of Hunan Province the Department of Education of (no. 10C0975) and the Major Project Item of Scientific Research of Hunan Province the Department of Education (no. 09A054).

\section{References}

1. Jemal A, Siegel R, Ward E, Hao Y, Xu J and Thun MJ: Cancer statistics, 2009. CA Cancer J Clin 59: 225-249, 2009.

2. Mor G, Fu HH and Alvero AB: Phenoxodiol, a novel approach for the treatment of ovarian cancer. Curr Opin Investig Drugs 7: 542-548, 2006.

3. Psyrri A, Kassar M, Yu Z, et al: Effect of epidermal growth factor receptor expression level on survival in patients with epithelial ovarian cancer. Clin Cancer Res 11: 8637-8643, 2005.

4. Ozols RF: Treatment goals in ovarian cancer. Int J Gynecol Cancer 15 (Suppl) 1: 3-11, 2005.

5. Cunha-Rodrigues M, Portugal S, Prudencio M, et al: Genisteinsupplemented diet decreases malaria liver infection in mice and constitutes a potential prophylactic strategy. PLoS One 3: e2732, 2008.

6. Zhou HB, Chen JM, Cai JT, Du Q and Wu CN: Anticancer activity of genistein on implanted tumor of human SG7901 cells in nude mice. World J Gastroenterol 14: 627-631, 2008.

7. Koo H, Schobel B, Scott-Anne K, et al: Apigenin and tt-farnesol with fluoride effects on S. mutans biofilms and dental caries. J Dent Res 84: 1016-1020, 2005. 
8. Fu XH, Wang L, Zhao H, Xiang HL and Cao JG: Synthesis of genistein derivatives and determination of their protective effects against vascular endothelial cell damages caused by hydrogen peroxide. Bioorg Med Chem Lett 18: 513-517, 2008.

9. Cancer Genome Atlas Research Network: Integrated genomic analyses of ovarian carcinoma. Nature 474: 609-615, 2011.

10. Wierstra I and Alves J: FOXM1, a typical proliferation-associated transcription factor. Biol Chem 388: 1257-1274, 2007.

11. Costa RH: FoxM1 dances with mitosis. Nat Cell Biol 7: 108-110, 2005.

12. Petrovic V, Costa RH, Lau LF, Raychaudhuri P and Tyner AL: FoxM1 regulates growth factor-induced expression of kinaseinteracting stathmin (KIS) to promote cell cycle progression. J Biol Chem 283: 453-460, 2008.

13. Wang IC, Chen YJ, Hughes DE, et al: FoxM1 regulates transcription of JNK1 to promote the G1/S transition and tumor cell invasiveness. J Biol Chem 283: 20770-20778, 2008.

14. Chen YJ, Dominguez-Brauer C, Wang Z, et al: A conserved phosphorylation site within the forkhead domain of FoxM1B is required for its activation by cyclin-CDK1. J Biol Chem 284: 30695-30707, 2009.

15. Park HJ, Carr JR, Wang Z, et al: FoxM1, a critical regulator of oxidative stress during oncogenesis. EMBO J 28: 2908-2918, 2009.

16. Wang Z, Ahmad A, Banerjee S, et al: FoxM1 is a novel target of a natural agent in pancreatic cancer. Pharm Res 27: 1159-1168, 2010.

17. Ai XH, Zheng X, Tang XQ, et al: Induction of apoptosis of human gastric carcinoma SGC-7901 cell line by 5, 7-dihydroxy8-nitrochrysin in vitro. World J Gastroenterol 13: 3824-3828, 2007.

18. Yang XH, Zheng X, Cao JG, Xiang HL, Liu F and Lv Y: 8-Bromo-7-methoxychrysin-induced apoptosis of hepatocellular carcinoma cells involves ROS and JNK. World J Gastroenterol 16: 3385-3393, 2010.

19. Wang Z, Banerjee S, Kong D, Li Y and Sarkar FH: Downregulation of Forkhead Box M1 transcription factor leads to the inhibition of invasion and angiogenesis of pancreatic cancer cells. Cancer Res 67: 8293-8300, 2007.

20. Francis RE, Myatt SS, Krol J, et al: FoxM1 is a downstream target and marker of HER 2 overexpression in breast cancer. Int J Oncol 35: 57-68, 2009.

21. Gemenetzidis E, Bose A, Riaz AM, et al: FOXM1 upregulation is an early event in human squamous cell carcinoma and it is enhanced by nicotine during malignant transformation. PLoS One 4: e4849, 2009.
22. McGovern UB, Francis RE, Peck B, et al: Gefitinib (Iressa) represses FOXM1 expression via FOXO3a in breast cancer. Mol Cancer Ther 8: 582-591, 2009.

23. Petrovic V, Costa RH, Lau LF, Raychaudhuri P and Tyner AL: Negative regulation of the oncogenic transcription factor FoxM1 by thiazolidinediones and mithramycin. Cancer Biol Ther 9: 1008-1016, 2010

24. Kwok JM, Myatt SS, Marson CM, Coombes RC, Constantinidou D and Lam EW: Thiostrepton selectively targets breast cancer cells through inhibition of forkhead box M1 expression. Mol Cancer Ther 7: 2022-2032, 2008.

25. Wang Z, Li Y, Ahmad A, et al: Down-regulation of Notch-1 is associated with Akt and FoxM1 in inducing cell growth inhibition and apoptosis in prostate cancer cells. J Cell Biochem 112: 78-88, 2011.

26. Barsotti AM and Prives C: Pro-proliferative FoxM1 is a target of p53-mediated repression. Oncogene 28: 4295-4305, 2009.

27. Ahmad A, Wang Z, Kong D, et al: FoxM1 down-regulation leads to inhibition of proliferation, migration and invasion of breast cancer cells through the modulation of extra-cellular matrix degrading factors. Breast Cancer Res Treat 122: 337-346, 2010.

28. Aprelikova O, Xiong Y and Liu ET: Both p16 and p21 families of cyclin-dependent kinase (CDK) inhibitors block the phosphorylation of cyclin-dependent kinases by the CDK-activating kinase. J Biol Chem 270: 18195-18197, 1995.

29. Sherr CJ: Mammalian G1 cyclins. Cell 73: 1059-1065, 1993

30. Wang IC, Chen YJ, Hughes D, et al: Forkhead box M1 regulates the transcriptional network of genes essential for mitotic progression and genes encoding the SCF (Skp2-Cks1) ubiquitin ligase. Mol Cell Biol 25: 10875-10894, 2005.

31. Zhao X, Ogunwobi OO and Liu C: Survivin inhibition is critical for Bcl-2 inhibitor-induced apoptosis in hepatocellular carcinoma cells. PLoS One 6: e21980, 2011.

32. Chowdhury S, Howell GM, Teggart CA, et al: Histone deacetylase inhibitor belinostat represses survivin expression through reactivation of transforming growth factor beta (TGFbeta) receptor II leading to cancer cell death. J Biol Chem 286: 30937-30948, 2011.

33. Rahman KW, Li Y, Wang Z, Sarkar SH and Sarkar FH: Gene expression profiling revealed survivin as a target of 3,3'-diindolylmethane-induced cell growth inhibition and apoptosis in breast cancer cells. Cancer Res 66: 4952-4960, 2006. 